\title{
Genotypic and Pathogenic Diversity Among Pea-Infecting Strains of Aphanomyces euteiches from the Central and Western United States
}

\author{
D. K. Malvick and J. A. Percich
}

Department of Plant Pathology, University of Minnesota, St. Paul 55108.

Current address of D. Malvick: W-L Research, Inc., 8701 W. U.S. Highway 14, Evansville, WI 53536.

Accepted for publication 29 May 1998.

\begin{abstract}
Malvick, D. K., and Percich, J. A. 1998. Genotypic and pathogenic diversity among pea-infecting strains of Aphanomyces euteiches from the central and western United States. Phytopathology 88:915-921.

Pathogenic and genotypic variability among four populations of Aphanomyces euteiches from individual fields in Minnesota, Wisconsin, and Oregon were investigated using pathogenicity and randomly amplified polymorphic DNA (RAPD) analyses. About 50 strains were isolated from each of two pea fields in Minnesota, and 11 and 6 strains from pea fields in Wisconsin and Oregon, respectively, using pea (Pisum sativum) as a baiting host. Pathogenic variability and host range were evaluated in greenhouse studies with five pea lines or cultivars having different levels of resistance to Aphanomyces root rot and one cultivar each of alfalfa and snap bean. All strains were pathogenic on one or more pea cultivars, and 18 and $14 \%$ were pathogenic on alfalfa and bean, respectively. Disease severity incited by different strains varied significantly on individual pea
\end{abstract}

ABSTRACT cultivars and on all hosts combined. The percentage of strains pathogenic on different hosts varied among locations. Genotypic variation among all 114 strains was evaluated with RAPD analysis. Ten decanucleotide primers detected 92 polymorphic bands. Cluster and principal coordinates analysis revealed one large group containing 102 of the 114 strains from all locations. Two closely related minor groups of strains (12 strains) were genotypically distinct, with about $55 \%$ similarity to the main group of 102 strains. The strains in the minor groups were all isolated from the Minnesota locations and were pathogenic on two disease-resistant pea breeding lines (MN313 and MN314). Estimates of genetic diversity based on RAPD analysis ranged from 0.24 to 0.33 within populations to 0.35 among all strains from all populations. A. euteiches populations were genotypically and phenotypically variable, but no distinct genotypic differences were identified among populations from the four isolated locations.

Additional keyword: oomycota.
The soilborne oomycota pathogen Aphanomyces euteiches Drechs. is common in many regions of the United States as well as in Canada, Europe, Asia, and Australia (25). It has been widely studied because of its importance as a root-infecting pathogen of legumes particularly pea (Pisum sativum L.), alfalfa (Medicago sativa L.), snap bean (Phaseolus vulgaris L.), and red clover (Trifolium pratense L.) $(5,9,23,25,27)$. Pea appears to be the crop most significantly impacted by Aphanomyces root rot, and fields with $100 \%$ loss are common $(11,25)$. Root rot diseases caused by A. euteiches can be reduced through rotation and avoidance of highly infested fields, but cannot be controlled commercially with chemicals or host resistance.

Characterization of the population structure of fungal pathogens is important for understanding an organism's biology and for the development of effective methods to control disease (16). Leung et al. (16) describe three components of population structure: (i) genetic variation among individuals in a population, (ii) partitioning of this variation in space and time, and (iii) phylogenetic relationships among individuals. Although many important soilborne fungal plant pathogens are known, their population structures are poorly understood (1). Problems encountered by plant breeders searching for resistance to Aphanomyces root rot may, in part, result from a poor understanding of the population structure of A. euteiches, which has not yet been elucidated. Efforts to breed pea for resistance to this pathogen have not resulted in the development of commercial pea varieties with resistance to A. euteiches; however, disease resistance holds promise for control of Aphanomyces root rot, as pea breeding lines with various levels of resistance have been devel-

Corresponding author: D. K. Malvick; E-mail: dmalvick@inwave.com

Publication no. P-1998-0713-01R

(c) 1998 The American Phytopathological Society oped $(4,10,11,15)$. It is not known if these pea lines resist isolates from different fields and regions in the United States. Further, the degree of pathogenic and genetic variation that exists within peainfecting isolates from different geographical regions is unknown. These components of population structure are important for understanding the biology of $A$. euteiches, selecting representative isolates for disease-resistance breeding, and effective utilization and deployment of resistant pea germ plasm.

Studies of pathogenic and genotypic variation among strains of A. euteiches isolated from pea, bean, alfalfa, and red clover have revealed distinct genotypic and phenotypic traits among strains associated with these different hosts $(9,13,18)$. Studies of variation among pea-infecting isolates of $A$. euteiches were limited to a few isolates and geographical areas $(2,3,13,20,31)$. These studies used pathogenicity on different pea cultivars to measure variation among isolates. The pea cultivars and breeding lines used had little variation for resistance to A. euteiches and, hence, limited ability to discriminate among strains with differing pathogenicity traits. Although pathogenicity is a valuable and key trait for study, it reveals only limited information on the actual diversity and genetic potential of pathogen populations, is subject to selection pressure from host plant populations, and is subject to many experimental constraints. Thus, in addition to testing pathogenic variability, more direct measures of genetic variation that detect selectively neutral loci must be used to help elucidate the population structure of $A$. euteiches and the potential for adaptation. Random amplified polymorphic DNA (RAPD) analysis $(32,33)$ has been used successfully to characterize genetic diversity within and among plants (14), bacteria (24), and different fungal species, strains, and populations $(7,8,12,21,26)$.

In this study, we assessed the population structure of $A$. euteiches in individual pea fields in Minnesota, Wisconsin, and Oregon. These are major regions for pea production in the United States, 
and Aphanomyces root rot is a serious disease in these areas (11, 25). Phenotypic diversity among strains and populations was characterized with pathogenicity assays on five pea lines, alfalfa, and bean. Genetic diversity was assessed with RAPD analysis. The primary objective of this study was to determine pathogenic and genotypic variation within and among pea-infecting populations of $A$. euteiches from four field sites in three states.

\section{MATERIALS AND METHODS}

Collection of soil samples and isolation of A. euteiches. Soil samples for isolation of $A$. euteiches were collected from randomly chosen locations throughout four fields (Table 1). In Minnesota, fields MN-A and MN-B were mapped to identify the point of origin of all strains. Fewer samples from Oregon and Wisconsin, relative to the Minnesota sites, were obtained, because of sample availability and difficulties in isolating A. euteiches. Strains of $A$. euteiches were isolated from soil samples using pea (8221 EP; Nunhems Seed Corp., Lewisville, ID) as a baiting host. Strains were isolated from roots using a semiselective medium (27) and characterized as A. euteiches according to the keys of Dick (6) and Scott (30). Strains originating from single zoospores were used for all analyses in this study and were obtained by inducing zoospore production in parental isolates (22), spreading zoospores on agar media, and subculturing single, germinating zoospore cysts. Results from other studies $(18,19)$ suggest that pathogenic and genotypic variation among zoospores from single strains are minor or insignificant compared with differences among different strains. All strains were maintained on corn meal agar (Difco Laboratories, Detroit) at $4^{\circ} \mathrm{C}$ and transferred at 3- to 6-month intervals.

Pathogenicity tests. Five pea lines or cultivars and one cultivar each of alfalfa and bean were used for pathogenicity tests (Table 2). A. euteiches strains $(N=114)$ were tested for host range and virulence on the five pea cultivars, snap bean, and alfalfa. Six previously characterized strains (P134-1, MF1-1, GB7-1, Ae467-1, GB1-3, and AOP34-1) that were isolated from and preferentially infect different hosts (pea, bean, and alfalfa) were included as positive and negative controls for pathogenicity $(9,18)$. Waxed paper cups $(160 \mathrm{ml})$ containing vermiculite were sown with 3 seeds of bean or pea, or 8 to 10 seeds of alfalfa. Alfalfa seed was sown in combination with host-specific Rhizobium meliloti. Experiments were conducted in a greenhouse maintained at $24 \pm 2{ }^{\circ} \mathrm{C}$ with a $12-\mathrm{h}$ light-dark cycle. Seedlings were grown 7 days prior to inoculation with 3,000 zoospores per cup. Plants were evaluated visually 14 days after inoculation for disease severity using a 0 to 5 scale, in which 0 is a healthy plant and 5 is a dead plant (4). Disease

TABLE 1. Collection sites for strains of Aphanomyces euteiches in Minnesota, Wisconsin, and Oregon

\begin{tabular}{lcll}
\hline Field & No. of strains & \multicolumn{1}{c}{ Location } & \multicolumn{1}{c}{ Cropping history } \\
\hline MN-A & 51 & 8 km S of Waseca, MN & Corn, pea, soybean \\
MN-B & 46 & $6 \mathrm{~km} \mathrm{SW}$ of Waseca, MN & Corn, pea, soybean \\
WI & 11 & Arlington, WI & Pea, unknown \\
OR & 6 & Athena, OR & Pea, winter wheat \\
\hline
\end{tabular}

TABLE 2. Code, characteristics, and source of pea (Pisum sativum), alfalfa (Medicago sativa), and bean (Phaseolus vulgaris) used for pathogenicity tests

\begin{tabular}{|c|c|c|c|c|}
\hline Code & Host & Line/cultivar & Resistance $^{\mathrm{a}}$ & Source \\
\hline P1 & Pea & MN313 & High & D. Davis, Univ. of Minnesota (4) \\
\hline $\mathrm{P} 2$ & Pea & MN314 & High & D. Davis, Univ. of Minnesota (4) \\
\hline P3 & Pea & $90-2079$ & Moderate & J. Kraft, USDA (15) \\
\hline P4 & Pea & WI-8904 & Moderate & E. Gritton, Univ. of Wisconsin (10) \\
\hline P5 & Pea & Little Marvel & Low & Burpee Seed Co. \\
\hline ALF & Alfalfa & Saranac & Low & Public variety \\
\hline BEAN & Bean & Early Gallatin & Low & Rogers Bros. Seed Co. \\
\hline
\end{tabular}

a Relative level of resistance/tolerance to root rot caused by Aphanomyces euteiches. severity (DS) values $\leq 2.5$ were considered to be a nonpathogenic interaction. These values were associated with minor root discoloration and signified a resistant response. There was no evidence of successful infection at DS $\leq 2.5$, and attempts to isolate $A$. euteiches and observe oospores were unsuccessful; however, isolations were successful and oospores were observed at DS values $>2.5$. Three replicate cups were used for each combination of plant cultivar or line and strain. The experiment was organized as a split-plot design with strain as the main plot factor and cultivar as the subplot. The entire experiment was repeated once. DS values among strains were evaluated with analysis of variance (ANOVA), and means were compared using Fisher's least significant difference (LSD) and Waller-Duncan K-ratio $t$ tests (SAS; SAS Institute, Inc., Cary, NC). Fresh biomass of whole plants was determined for pea and bean to measure the effect of the pathogens on whole-plant responses, and percent loss of biomass of inoculated versus noninoculated plants was calculated.

Polymerase chain reaction amplifications and RAPD assays. Aphanomyces strains were grown at $22^{\circ} \mathrm{C}$ in peptone glucose broth (22) amended with $40 \mu \mathrm{g}$ of rifampicin per ml (Sigma Chemical Co., St. Louis) for 6 days. DNA was extracted (29), and then DNA concentrations were measured with a fluorometer (Hoeffer model TKO 100; Hoeffer Scientific Instruments, San Francisco) and standardized for all strains prior to RAPD analyses. Fifty decanucleotide primers obtained from the University of British Columbia Biotechnology Laboratory (set 100/1) were screened using DNA from five test strains of A. euteiches that represented different pathotypes and hosts of origin. Ten primers used for this study (Table 3) were selected based on the number of clear, reproducible bands amplified from the test strains and the production of polymorphic bands that distinguished the test strains. DNA from 114 strains of Aphanomyces (Table 4) was amplified using each of the 10 primers (18). Each 25- $\mu \mathrm{l}$ amplification reaction contained $15 \mathrm{ng}$ of primer, $2 \mathrm{mM} \mathrm{MgCl}_{2}, 2.5 \mathrm{ng}$ of genomic DNA, and 0.75 units of Taq DNA polymerase. Amplifications were conducted in a Tempcycler II (Coy Lab. Products, Inc., Grass Lake, MI) programmed for 1 cycle of $94^{\circ} \mathrm{C}$ for $30 \mathrm{~s} ; 46$ cycles of $94^{\circ} \mathrm{C}$ for $40 \mathrm{~s}, 36^{\circ} \mathrm{C}$ for $1 \mathrm{~min}$, and $72^{\circ} \mathrm{C}$ for $2 \mathrm{~min}$; and 1 cycle of $72^{\circ} \mathrm{C}$ for $7 \mathrm{~min}$. Amplified samples $(11 \mu \mathrm{l})$ were loaded into composite gels made with $0.6 \%$ agarose (Fisher Scientific Co., Pittsburgh) and $0.44 \%$ Synergel (Diversified Biotech, Boston) in 1X TAE (40 mM Tris, $1.3 \mathrm{mM}$ EDTA, and $0.11 \%$ glacial acetic acid; $\mathrm{pH}$ 8.0) buffer. Electrophoresis was conducted at $6.8 \mathrm{~V} / \mathrm{cm}$ for $2.2 \mathrm{~h}$. Reproducibility of RAPD analyses was tested by amplifying DNA samples from a randomly chosen set of 15 of the strains (13\% of total) 2 to 3 times and strain P134-1 34 times with each of the 10 primers, and

TABLE 3. Random amplified polymorphic DNA primers used for analysis of 114 strains of Aphanomyces euteiches and the number of bands detected and scored with each primer

\begin{tabular}{|c|c|c|c|c|}
\hline Code $^{a}$ & Sequence $^{b}$ & $\begin{array}{l}\text { No. of bands } \\
\text { (range) }^{c}\end{array}$ & $\begin{array}{l}\text { Polymorphic } \\
\text { bands }^{\mathrm{d}}\end{array}$ & $\begin{array}{c}\text { Total } \\
\text { bands }\end{array}$ \\
\hline 1 & CCTGGGCTTC & $6.2(6-7)$ & 1 & 7 \\
\hline 2 & CCTGGGCTTG & $7.4(5-8)$ & 12 & 14 \\
\hline 9 & CCTGCGCTTA & $4.8(3-9)$ & 16 & 17 \\
\hline 12 & CCTGGGTCCA & $6.7(6-8)$ & 8 & 10 \\
\hline 16 & GGTGGCGGGA & $3.4(3-6)$ & 5 & 7 \\
\hline 23 & CCCGCCTTCC & $8.1(5-10)$ & 9 & 13 \\
\hline 25 & ACAGGGCTCA & $6.2(5-9)$ & 8 & 11 \\
\hline 31 & CCGGCCTTCC & $9.0(5-10)$ & 15 & 15 \\
\hline 33 & CCGGCTGGAA & $4.2(2-6)$ & 8 & 9 \\
\hline 34 & CCGGCCCCAA & $7.8(5-10)$ & 10 & 12 \\
\hline Total & & & 92 & 115 \\
\hline
\end{tabular}

a Code for primer sequence from the University of British Columbia.

b $5^{\prime}$ to $3^{\prime}$ primer sequence.

c Mean number of bands amplified per strain and range of bands per strain

d Number of polymorphic bands in all strains.

e Total number of bands in all strains. 
resulting banding patterns were compared. RAPD banding patterns were analyzed as binary data, with 1 and 0 representing the presence or absence of clear bands, respectively. RAPD data were analyzed using the DICE coefficient with the computer software program NTSYS-pc 1.6 (Exeter Software, Setauket, NY). A phenogram based on the unweighted pair group method with arithmetic average was produced from all scorable amplified fragments. The Mxcomp routine in NTSYS-pc 1.6 was used to assess the degree of fit between the data and graphical representations, and the cophenetic correlation $(r=0.98)$ indicated a good fit. Bootstrap analysis using the computer program WinBoot (34) was used to evaluate the robustness of the phenogram groupings produced by cluster analysis of the RAPD data. The RAPD phenogram was reconstructed 300 times by repeated sampling with replacement, and the frequency with which groups formed was used to indicate the strength of the groups. Principal coordinates analysis using the DICE coefficient was performed with the NTSYS-pc 1.6 software to provide another means of testing relationships among strains. Genetic diversity within populations was estimated with RAPD data as described by Lynch and Milligan (17). Useful estimates of population genetic parameters from large and small sample sizes can be achieved with RAPD data, provided the analysis is restricted to bands whose observed frequency is less than $1-(3 / N)$, in which $N$ is the number of sampled individuals (17).

\section{RESULTS}

Pathogenicity and virulence characteristics. The 114 strains of $A$. euteiches were isolated from pea and were pathogenic (DS rating $>2.5$ ) on one or more of the five pea cultivars; 18 and $14 \%$ were pathogenic on alfalfa and bean, respectively (Tables 4 and 5). The mean DS ratings for all strains on each of the seven plant hosts were 1.8 to 4.1 (Fig. 1A). The percentage of all strains tested from all sites combined that were pathogenic on the five individual pea cultivars varied from 16 to $97 \%$ (Table 5). Cultivars P4 and P5 were highly susceptible to 96 to $97 \%$, respectively, of the strains of $A$. euteiches tested in this study (Tables 4 and 5). The other three pea cultivars, in order of increasing resistance, were $\mathrm{P} 3, \mathrm{P} 1$, and $\mathrm{P} 2$, based on DS and percentage of all strains that were pathogenic on these pea lines (Fig. 1A, Tables 4 and 5). ANOVA of the DS for all plant cultivars in two experiments with three replications each revealed significant $(P=0.05)$ differences among strains and plant hosts, and significant $(P=0.05)$ strain $\times$ cultivar interactions. Many strains incited significantly different DS values $(P=0.01)$ on individual hosts. Measurements of fresh biomass of whole inoculated and noninoculated plants was also determined, and the mean percent losses of biomass (and standard deviation) due to disease for all strains on P1, P2, P3, P4, P5, and bean were 12.6 (1.2), 6.7 (1.0), 15.3 (1.6), 32.7

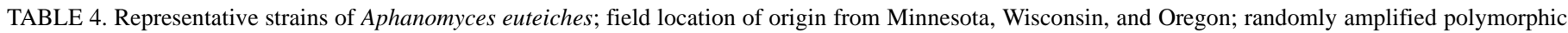

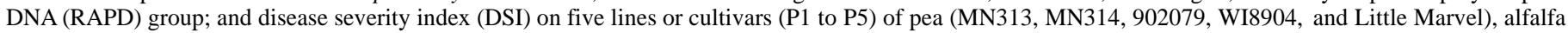
(Saranac), and bean (Early Gallatin)

\begin{tabular}{|c|c|c|c|c|c|c|c|c|c|}
\hline \multirow[b]{2}{*}{ Strain } & \multirow[b]{2}{*}{ Origin $^{a}$} & \multirow[b]{2}{*}{ Group $^{b}$} & \multicolumn{7}{|c|}{$\mathrm{DSI}^{\mathrm{c}}$} \\
\hline & & & $\mathrm{P} 1$ & $\mathrm{P} 2$ & P3 & $\mathrm{P} 4$ & P5 & Alfalfa & Bean \\
\hline MO1-2 & $\mathrm{MN}-\mathrm{A}^{\mathrm{d}}$ & Main & 1.3 & 1.5 & 1.5 & 4.0 & 4.7 & 3.5 & 0.7 \\
\hline MO3-1 & MN-A & MG-II & 4.2 & 2.6 & 3.7 & 4.0 & 3.7 & 2.2 & 0.0 \\
\hline MO10-1 & MN-A & MG-II & 3.4 & 3.4 & 3.7 & 4.3 & 4.4 & 3.5 & 1.5 \\
\hline MM36-1 & MN-A & Main & 3.2 & 2.3 & 3.8 & 4.7 & 4.5 & 3.2 & 1.7 \\
\hline MM52-2 & MN-A & MG-I & 3.7 & 3.7 & 4.2 & 4.2 & 4.7 & 1.8 & 1.0 \\
\hline MM57-1 & MN-A & Main & 3.3 & 2.2 & 3.2 & 4.5 & 4.2 & 2.7 & 3.5 \\
\hline MM143-1 & MN-A & Main & 1.3 & 1.7 & 2.7 & 4.2 & 3.5 & 0.0 & 2.5 \\
\hline MM192-1 & MN-A & Main & 2.5 & 1.5 & 2.5 & 4.2 & 3.3 & 2.5 & 2.0 \\
\hline MM54-1 & $M N-B^{e}$ & Main & 2.3 & 2.4 & 3.5 & 5.0 & 5.0 & 2.7 & 2.3 \\
\hline MM96-1 & MN-B & MG-II & 4.0 & 3.8 & 4.0 & 4.3 & 4.3 & 3.0 & 1.2 \\
\hline MM98-1 & MN-B & Main & 4.0 & 3.3 & 3.6 & 4.3 & 4.8 & 2.8 & 2.5 \\
\hline MM100-1 & MN-B & Main & 2.0 & 2.0 & 3.0 & 3.8 & 4.8 & 2.5 & 3.7 \\
\hline MM126-1 & MN-B & MG-I & 4.2 & 3.8 & 4.3 & 4.3 & 4.8 & 2.8 & 0.0 \\
\hline MM158-3 & MN-B & MG-II & 3.0 & 1.5 & 1.9 & 3.8 & 1.6 & 0.8 & 0.3 \\
\hline MM159-2 & MN-B & Outlier & 2.9 & 1.8 & 2.0 & 2.5 & 1.2 & 0.0 & 1.0 \\
\hline MM187-1 & MN-B & Main & 3.0 & 2.4 & 4.0 & 4.8 & 4.8 & 3.2 & 3.0 \\
\hline MA1-3 & $\mathrm{WI}^{\mathrm{f}}$ & Main & 2.3 & 1.8 & 2.3 & 3.0 & 3.7 & 1.5 & 0.3 \\
\hline MA3-1 & WI & Main & 3.1 & 2.7 & 3.5 & 4.8 & 4.7 & 1.1 & 1.7 \\
\hline MA8B-1 & WI & Main & 3.3 & 2.3 & 3.7 & 5.0 & 5.0 & 3.2 & 0.7 \\
\hline MA11-1 & WI & Main & 3.1 & 3.2 & 4.8 & 4.7 & 4.8 & 0.0 & 1.4 \\
\hline OR1-1 & $\mathrm{OR}^{\mathrm{g}}$ & Main & 2.2 & 1.3 & 2.4 & 3.8 & 4.7 & 1.7 & 3.0 \\
\hline OR6-1 & OR & Main & 2.5 & 2.5 & 3.2 & 4.8 & 5.0 & 2.2 & 3.4 \\
\hline OR10-1 & OR & Main & 3.6 & 3.8 & 4.2 & 5.0 & 4.2 & 2.0 & 1.0 \\
\hline P134-1 & WI-X & MG-I & 2.8 & 3.3 & 3.8 & 3.8 & 3.6 & 1.4 & 1.0 \\
\hline MF1-1 & WI-X & $\mathrm{NT}^{\mathrm{h}}$ & 0.0 & 0.0 & 0.0 & 0.3 & 0.0 & 2.7 & 1.7 \\
\hline GB1-3 & WI-X & NT & 0.0 & 0.0 & 0.0 & 0.0 & 0.0 & 0.0 & 3.4 \\
\hline Control & Noninoculated & & 0.0 & 0.0 & 0.0 & 0.0 & 0.0 & 0.0 & 0.0 \\
\hline $\operatorname{LSD}(P=0$ & & & 1.0 & 0.9 & 1.0 & 0.9 & 0.9 & 1.1 & 1.3 \\
\hline
\end{tabular}

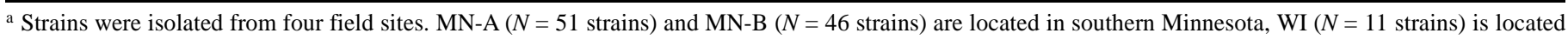
in southern Wisconsin, and OR ( $N=6$ strains) is located in northcentral Oregon.

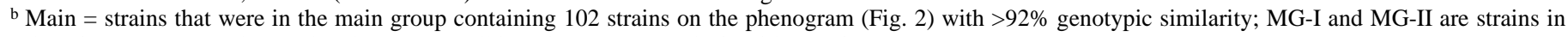
the minor groups I and II on the phenogram. All based on RAPD analysis with 10 primers.

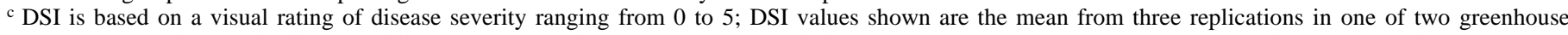
experiments and were significantly different $(P=0.05)$ for some strains on individual plant hosts and on all seven hosts combined. Results from the second experiment were similar.

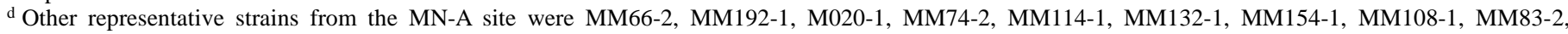
MM62-3, MM65-2, MM75-1, and MM76-1.

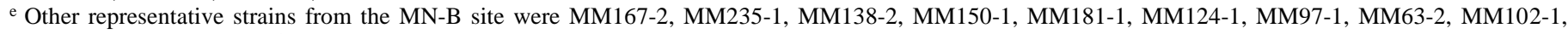
MM194-1, MM234-1, and MM113-1.

f Another representative strain from the WI site was MA2-1.

$\mathrm{g}$ Another representative strain from the OR site was OR3-2.

${ }^{\mathrm{h}} \mathrm{NT}=$ not tested. 
(1.9), $30.4(3.0)$, and $14.3 \%(6.4 \%)$, respectively. The relative values for percent loss on the different cultivars having different levels of resistance corresponded to the relative DS levels and the percentage of strains that were pathogenic on these same cultivars (Fig. 1A, Table 4).
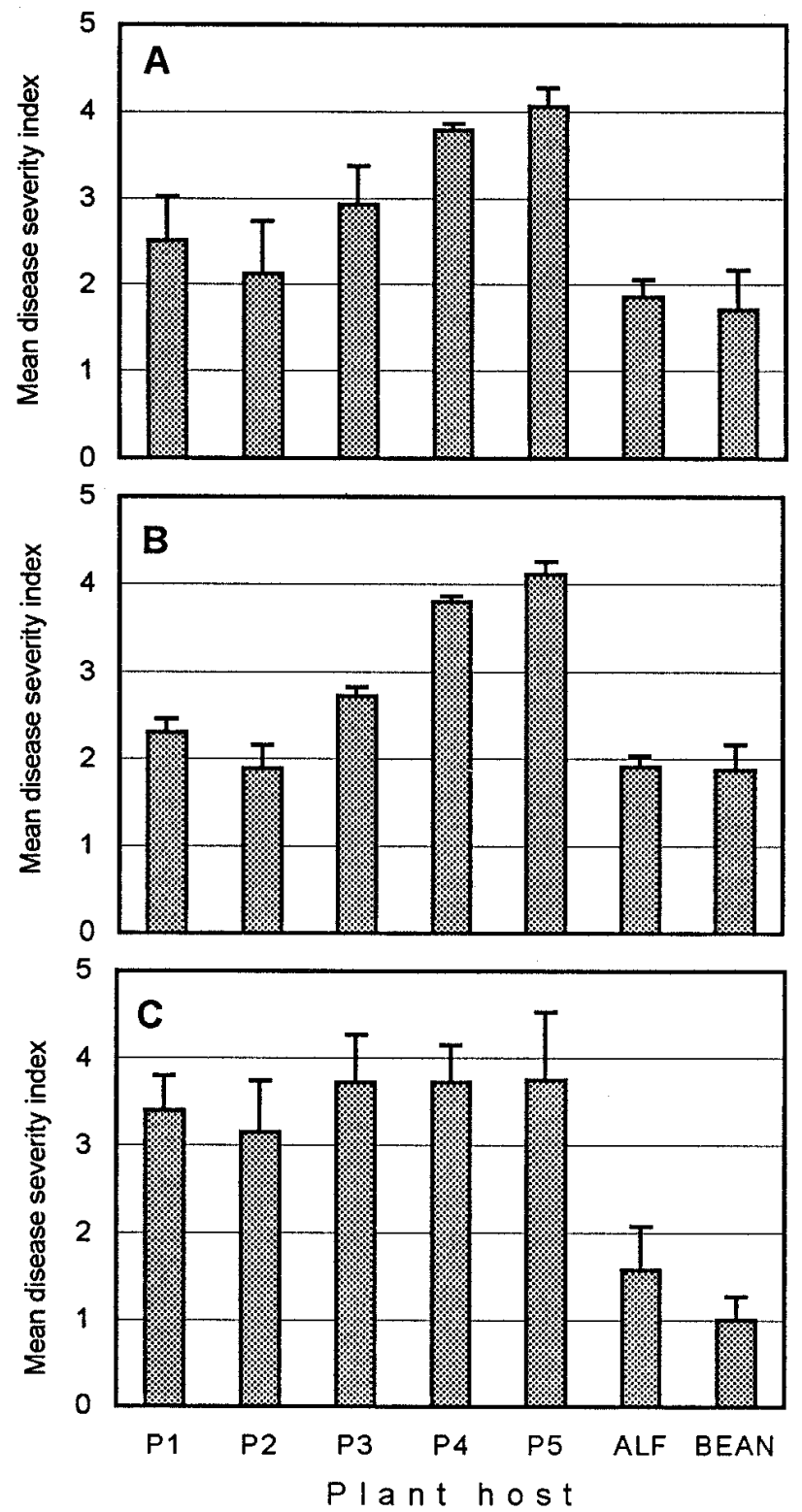

Fig. 1. Mean disease severity index for five pea lines or cultivars (P1 to P5), alfalfa (ALF), and bean after inoculation with A, 114 strains of Aphanomyces euteiches; $\mathbf{B}$, only those strains in the major randomly amplified polymorphic DNA (RAPD) group (Fig. 3); and C, only those strains in the minor RAPD groups (Fig. 3). Error bars represent standard deviation.
Pathogenicity assays with five cultivars or lines of pea, bean, and alfalfa indicated that pathogenicity traits differed among populations of $A$. euteiches from the $\mathrm{MN}-\mathrm{A}, \mathrm{MN}-\mathrm{B}$, Wisconsin, and Oregon sites (Table 5); however, unequal sample numbers weaken parallel comparisons between sites. For example, $67 \%$ of the strains from Oregon and $10 \%$ from the MN-A location were pathogenic on the root rot-resistant pea line P2 (Table 5). All strains from each location were compared with all strains from each other location based on the DS they incited on the seven plant hosts. From 60 to $75 \%$ (mean value) of strains from any one location were significantly different $(P=0.05)$ than all strains from other locations.

Genotypic variation among strains based on RAPD analysis. RAPD analysis was an informative and reproducible method to compare background genotypes and estimate genotypic variation among strains from the four locations. Examples of RAPD banding patterns generated with two primers are shown in Figure 2. All strains differed by at least one band when all bands generated by the 10 primers were combined. Most $(80 \%)$ of the RAPD bands detected were polymorphic in the group of 114 strains. Individual RAPD primers generated from 7 to 17 amplified fragments for the group of 114 strains analyzed (Table 3 ). The 10 individual primers alone detected 92 polymorphic amplified fragments (Table 3 ), and all primers combined detected 114 different RAPD genotypes among the 114 strains studied. Reproducibility was demonstrated by replicate amplification of the same banding pattern in a subset (15\%) of all strains with all 10 primers, and by repeated $(N=34)$ amplification of DNA extracted once from the strain P134-1. Genetic similarity among all strains, based on the amplified fragments generated with the 10 primers, is shown in a phenogram (Fig. 3). Principal coordinates analysis revealed the same genotypic clusters among all strains (data not shown). Most (102 of 114) of the strains clustered into one main group, and 11 strains clustered into two minor groups, suggesting that most pea-infecting strains of $A$. euteiches are genetically similar from the four fields sampled in the three states. Strains in the main group were at least 93\% similar. One strain (MM159-2) was 70\% similar to the main group, and the 11 strains in two closely related minor groups were about $50 \%$ similar to the main group of strains. Bootstrap analysis revealed that the division between the major and minor groups was robust ( $97 \%$ confidence estimate); however, the division between the two minor groups was not strong (52\% confidence).

The strains in the minor groups were pathogenic (DS > 2.5) on the resistant pea lines P1 and P2 (Fig. 1C). All strains in the minor RAPD groups were from the Minnesota locations and were pathogenic on P1, and $82 \%$ were pathogenic on P2; whereas only 37 and $16 \%$ of all strains tested were pathogenic on $\mathrm{P} 1$ and $\mathrm{P} 2$, respectively. Not all strains that were pathogenic on P1 and P2, however, were in the minor groups. In the major group, eight of the strains (7.8\%) were pathogenic on the pea lines P1 and P2. Most strains in all RAPD groups were pathogenic on P3, P4, and P5 (Table 4).

The between-site differences detected with pathogenicity assays were not detected with RAPD analysis. RAPD analyses did not reveal distinct genotypic differences among the strains from the four different field locations (i.e., genetic markers were not detected

TABLE 5. Percentage of strains of Aphanomyces euteiches from four individual locations in Minnesota, Wisconsin, and Oregon and all four locations combined that were pathogenic ${ }^{\mathrm{a}}$ on five pea lines or cultivars (P1 to P5), alfalfa, and bean

\begin{tabular}{|c|c|c|c|c|c|c|c|}
\hline \multirow[b]{2}{*}{ Location $^{\mathrm{b}}$} & \multicolumn{7}{|c|}{ Plant host strains pathogenic (\%) } \\
\hline & $\mathrm{P} 1$ & $\mathrm{P} 2$ & P3 & $\mathrm{P} 4$ & P5 & Alfalfa & Bean \\
\hline MN-A & 45 & 10 & 63 & 100 & 100 & 18 & 10 \\
\hline MN-B & 28 & 17 & 69 & 96 & 93 & 15 & 22 \\
\hline WI & 18 & 9 & 55 & 82 & 91 & 18 & 0 \\
\hline OR & 67 & 67 & 67 & 100 & 100 & 33 & 17 \\
\hline All locations ${ }^{c}$ & 37 & 16 & 65 & 96 & 97 & 18 & 14 \\
\hline
\end{tabular}

a Incited disease severity $>2.5$.

b Sample sizes for the sites: MN-A $(N=51), \mathrm{MN}-\mathrm{B}(N=46)$, WI $(N=11)$, and OR $(N=6)$.

c All strains $(N=114)$ from all four locations combined. 
that could cluster strains based on geographical origin). Most strains were more than $88 \%$ genotypically similar (Fig. 3). Estimates of genetic diversity varied depending on whether all markers or only markers with frequencies less than $1-(3 / N)$ were included in the analysis (Table 6). Using this subset of markers can reduce bias in estimates of population genetic parameters when sample sizes are small (17). Estimates of relative genetic diversity (D) within populations based on RAPD markers whose frequencies are less
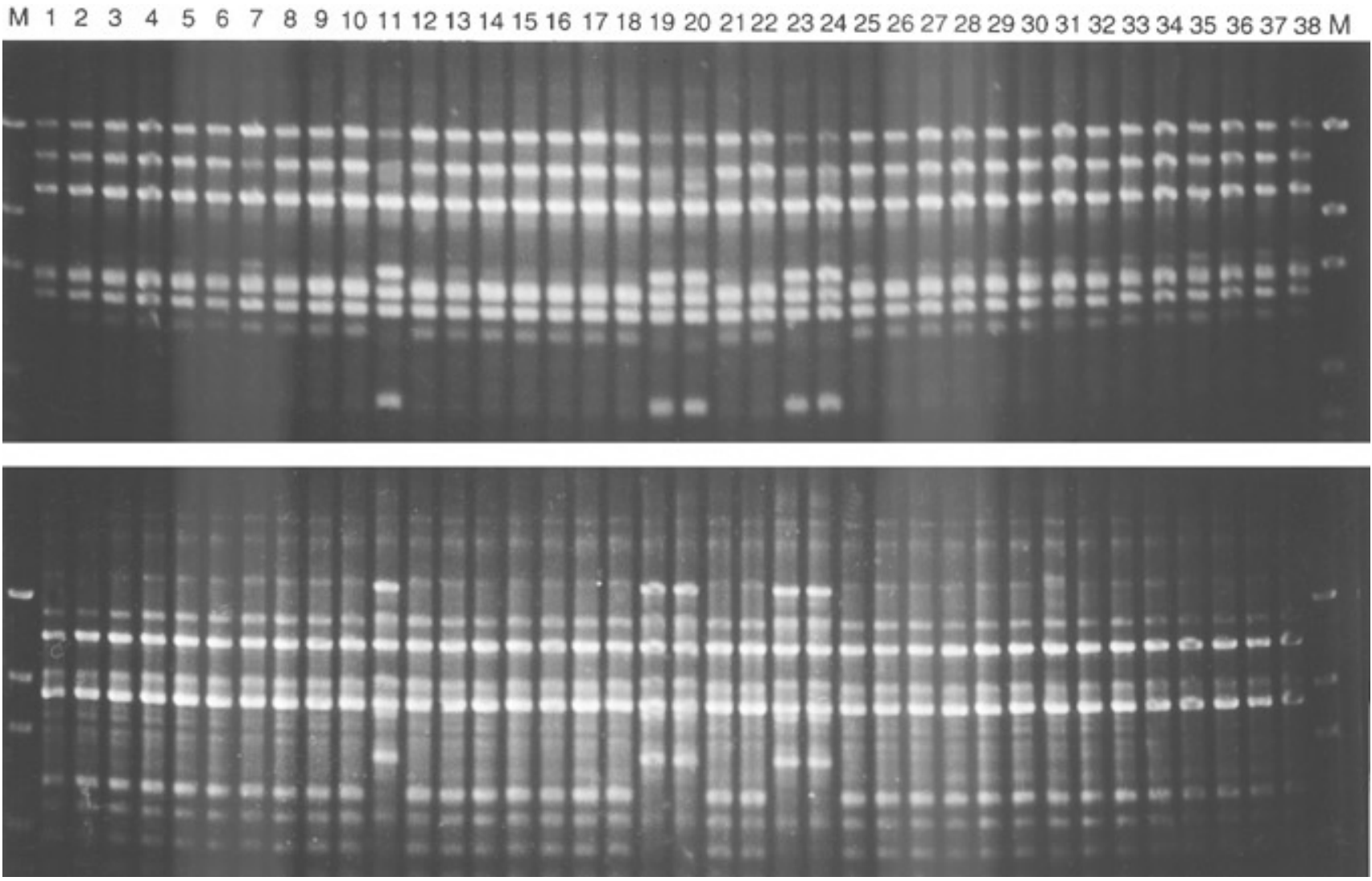

Fig. 2. Randomly amplified polymorphic DNA (RAPD) banding patterns generated with primer 25 (ACAGGGCTCA) (top) and primer 34 (CCGGCCCCAA) (bottom) from 38 strains of Aphanomyces euteiches isolated from four fields in Minnesota (MN-A and MN-B), Oregon (OR), and Wisconsin (WI). The top five bands in the pGEM (Promega Corp.) molecular size markers (M) in the first and last lanes are 2.6, 1.4, 1.2, 0.7, and $0.5 \mathrm{~kb}$. Amplified DNA from strains (Table 4, an "M" prefix and the suffix are omitted) in the lanes (L) in order from left to right are L1, M66; L2, M167; L3, M235; L4, M138; L5, M181; L6, M192; L7, O20; L8, M124; L9, M97; L10, M63; L11, M171; L12, M56; L13, M74; L14, M102; L15, M114; L16, M132; L17, M154; L18, M79; L19, O3; L20, P134; L21, M54; L22, M194; L23, M234; L24, M158; L25, M108; L26, M187; L27, M150; L28, M83; L29, A2; L30, 01; L31, OR3; L32, M57; L33, M62; L34, M113; L35, M65; L36, M75; L37, M76; and L38, M53.

Genetic Similarity

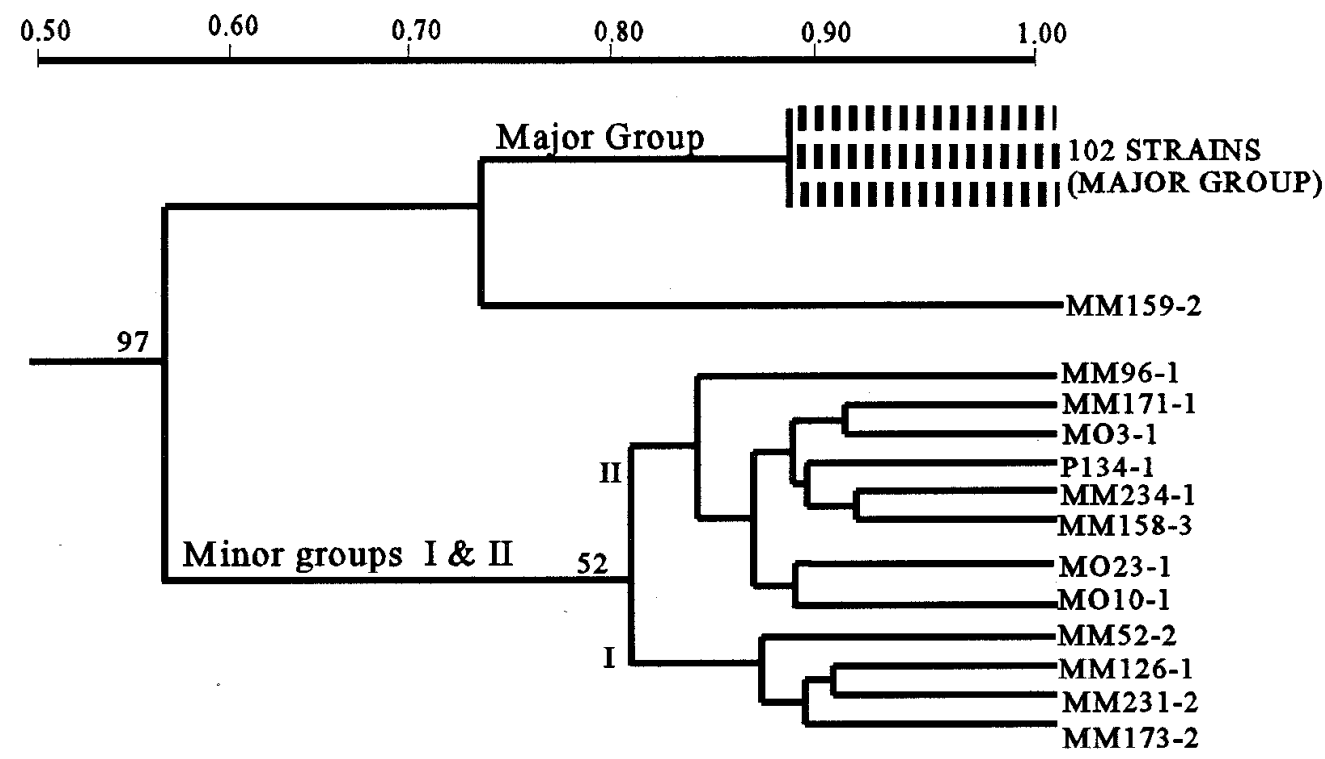

Fig. 3. Phenogram showing genetic similarity among 114 strains of Aphanomyces euteiches from four field locations based on randomly amplified polymorphic DNA (RAPD) analysis with 10 primers. Strain P134-1 was included as a control. RAPD groups corresponded to pathogenicity traits, not to geographical origin. All strains in the minor RAPD groups except MM158-3 were pathogenic on the resistant pea breeding lines P1 and P2. Numbers on key branches of the clusters represent the percentage of times the groups occurred out of 300 bootstrap iterations. 
than $1-(3 / N)$ ranged from $\mathrm{D}=0.24$ to 0.33 , and overall $\mathrm{D}=0.35$ (Table 6). Thus, all locations appeared to contain diverse populations with similar levels of relative genetic diversity. Analysis of the geographical variation was taken to a fine scale in the MN-A and MN-B field sites by mapping the location of origin of all strains. The strains that occurred in the minor RAPD groups on the phenogram (Fig. 3) and were pathogenic on the resistant pea lines P1 and P2 were clustered in approximately $10 \%$ of the area in the two $\mathrm{MN}$ sites (data not shown). Additional studies are needed to determine the significance of this observation.

\section{DISCUSSION}

The primary aim of this research was to investigate variation within and among pea-infecting populations of A. euteiches from fields in Minnesota, Wisconsin, and Oregon by using pathogenicity assays and molecular markers. This report provides information on the population structure and biology of this organism, including phenotypic and genotypic variability across and within geographical boundaries. This information may be of value to plant breeders and growers in their efforts to develop disease-resistant vegetable varieties and successfully produce pea, bean, and alfalfa crops. Populations of strains that overcome the resistance in pea breeding lines P1 and P2 exist in all areas studied, and future planting of cultivars with the resistance traits found in these two breeding lines could promote an increase in the population of strains that can overcome this resistance. The ability of strains isolated from pea to infect alfalfa and bean also suggests that management of Aphanomyces root rot will partially depend on careful use of pea, bean, and alfalfa in rotational schemes.

Strains of A. euteiches, which were isolated from four fields using pea as a baiting host, exhibited variations in pathogenicity on the pea, alfalfa, and bean hosts used in this study, and these variations appear dependent on field location. The results contrast with previous studies. Holub et al. (13) reported that 59, 97, and 0\% of 37 strains isolated from pea (pea strains) were pathogenic (DS > 2.5) on pea, alfalfa, and green bean, whereas 96,18 , and $14 \%$ of all strains were pathogenic on the same hosts, respectively, in this study. The differing results in the two studies may be explained by the use of different strains from different locations and contrasting types of planting medium and inoculum for pathogenicity testing. Pfender et al. (28) reported that some pea strains infected bean, but the infection was much less severe than that caused by bean strains. The current study shows that pea strains can cause symptoms on bean (e.g., necrosis extending up the hypocotyl) similar to those caused by aggressive strains isolated from bean.

The five pea lines used in this study were chosen based on their different levels of resistance to A. euteiches $(4,10,15)$. Results confirm these different levels of resistance and suggest that these pea lines can distinguish different pathogenicity phenotypes among strains. The pea breeding lines $\mathrm{P} 1$ and $\mathrm{P} 2$ are among the best sources of resistance to Aphanomyces root rot currently available. These lines were resistant to many different strains of A. euteiches from different pea-growing areas, even under the favorable environmental

TABLE 6. Estimates of genetic diversity within populations of Aphanomyces euteiches from four locations and all locations combined, based on randomly amplified polymorphic DNA markers produced with 10 primers

\begin{tabular}{lccccc}
\hline & \multicolumn{2}{c}{ Diversity estimates $^{\mathrm{a}}$} & & \multicolumn{2}{c}{ Polymorphic markers } \\
\cline { 2 - 3 } \cline { 5 - 6 } Population & All & $<1-3 / N$ & & Number & $\%$ \\
\hline MN-A & 0.19 & 0.24 & & 90 & 79 \\
MN-B & 0.23 & 0.29 & & 85 & 75 \\
WI & 0.20 & 0.33 & & 33 & 43 \\
OR & 0.18 & 0.28 & & 24 & 31 \\
All populations & 0.32 & 0.35 & & 92 & 80 \\
\hline
\end{tabular}

a Diversity estimates with two subsets of markers: all markers, and markers with frequency $<1-3 / N$. conditions for infection used in this study. The results also demonstrate that all locations contain strains that are pathogenic to P1 and $\mathrm{P} 2$, and some locations appear to have a higher percentage of these pathogens in the population than other locations. Although $\mathrm{P} 1$ and $\mathrm{P} 2$ are useful sources of resistance traits, plans for deployment of these traits should consider the likely occurrence of populations of $A$. euteiches that can overcome these resistance traits. The results highlight the need to continue seeking new sources of disease resistance.

Genetic variation among 114 strains of A. euteiches was assessed using RAPD analysis, which we assume primarily detects selectively neutral DNA markers at coding and noncoding locations dispersed throughout the genome. Based on RAPD analysis, there appears to be much minor genetic variability among strains in the four populations tested. The genetic similarity, however, is high (>90\%) among most strains, with the exception of a small group of strains in genetically distinct subpopulations that were isolated from locations MN-A and MN-B. RAPD analysis in a previous study (18) revealed genotypic differences among strains of A. euteiches that corresponded to their host of origin and pathogenicity on bean and alfalfa. In the current study, however, genetic differences corresponding to pathogenicity on alfalfa or bean were not detected with RAPD analysis using many of the same primers that were used previously. This suggests that genotypic differences among bean and alfalfa pathotypes characterized in the previous study corresponded more directly to host of origin than to pathogenicity on bean and alfalfa. This result may support the hypothesis that host plants and agricultural practice promote reproductive isolation and genotypic differentiation among strains of A. euteiches.

Indirect relationships were noted between RAPD results, pathogenicity, and geographical origin. All strains in the minor RAPD groups originated from the $\mathrm{MN}-1$ and $\mathrm{MN}-2$ sites and were pathogenic on the resistant pea lines $\mathrm{P} 1$ and $\mathrm{P} 2$, suggesting that the RAPD analysis detected genetic markers that occur in the Minnesota sites and are associated with pathogenicity on these two pea lines. This also suggests that some strains with the ability to overcome resistance in lines $\mathrm{P} 1$ and $\mathrm{P} 2$ have distinct genetic markers. If these markers are phenotype specific, they may be useful for development of a DNA-based method to identify strains with particular pathogenicity traits. In addition, the origin of the strains in the minor RAPD groups were mapped in field sites MN-A and $\mathrm{MN}-\mathrm{B}$ and appear to be clustered in the fields (data not shown). This indicates that strains in the minor RAPD groups from sites $\mathrm{MN}-\mathrm{A}$ and $\mathrm{MN}-\mathrm{B}$ may be clones that originated at one point in each field and are dispersing radially. Further sampling and analysis is required to test this hypothesis. The apparent clustering of strains with particular genotypic and pathogenic traits in the Minnesota fields also suggests that populations are not genetically uniform across fields, and "hot spots" for disease may result, at least partially, from differing populations of A. euteiches.

A goal of this study was to investigate genotypic variation, a key component of population structure, within and between fields in Minnesota, Wisconsin, and Oregon. The estimates of genetic diversity within fields were all relatively high. These estimates are based on the assumptions that (i) marker bands from different alleles do not comigrate on gels and (ii) each locus can be treated as a two-allele system, and only one of the alleles at each locus is amplified by the polymerase chain reaction (17). The first assumption was confirmed in this study with four fragments $(0.5-, 1.0-$, $1.1-$, and $1.3-\mathrm{kb}$ pairs amplified with primers 2,16 , and 25) used in DNA hybridization experiments (data not shown). The second assumption was not tested, because genetic analysis cannot yet be done with crosses between A. euteiches strains, and RAPD data cannot distinguish heterozygotes from homozygotes. Interpretations of these data must also consider that different RAPD genotypes may reflect either phenotype or heterozygosity in diploid organisms such as Aphanomyces spp. Similar levels of estimated genetic diversity from individual fields $(\mathrm{D}=0.24$ to 0.33$)$ and all fields 
combined $(\mathrm{D}=0.35)$ suggest that most genotypic diversity in U.S. populations of $A$. euteiches in the Midwest and Northwest may exist within localized populations. A value of $\mathrm{D}=1.0$ indicates high diversity, such that any two alleles at a locus sampled from a population are different, while $\mathrm{D}=0$ indicates genetically uniform populations, in which all individuals are identical. These estimates of genetic diversity, in addition to the observation that all strains had a unique RAPD genotype (banding pattern) based on all 10 primers combined, may suggest that the populations studied are nonclonal and heterothallic. Alternatively, there may be other explanations (i.e., clones may have formed into lineages). Furthermore, RAPD analysis did not reveal distinct genetic differences between strains or populations from the different locations sampled. Even the Rocky Mountains appeared neither to act as a geographical barrier to an isolate nor promote population differentiation between strains in Oregon and the Midwest, suggesting that humanassisted movement of pathogen genotypes may have occurred.

Populations of A. euteiches isolated from pea are pathogenically, genotypically, and geographically variable. The variability may explain some of the difficulties encountered historically in developing pea cultivars with resistance to Aphanomyces root rot as well as other methods for disease management. The problems of controlling Aphanomyces root rot and understanding the biology of A. euteiches have long been challenging. Results from this study help to elucidate the population biology of this recalcitrant pathogen and clarify some of the challenges growers and plant breeders must overcome as they work to minimize disease losses due to A. euteiches.

\section{ACKNOWLEDGMENTS}

Published as contribution no. 192200020 of the series of the Minnesota Agricultural Experiment Station on research conducted under Project 22-93, supported by funding from the USDA Cool Season Food Legume Research Program. We thank the Crosby Fellowship for partial support provided for early stages of this study; $\mathrm{C}$. Grau for providing valuable input; and J. Kraft and B. Rand for providing soil samples used for isolation of Aphanomyces euteiches from Oregon and Wisconsin, respectively.

\section{LITERATURE CITED}

1. Anderson, J. B., and Kohn, L. M. 1995. Clonality in soilborne plantpathogenic fungi. Annu. Rev. Phytopathol. 33:369-391.

2. Beute, M. K., and Lockwood, J. L. 1967. Pathogenic variability in Aphanomyces euteiches. Phytopathology 57:57-60.

3. Carley, H. E. 1970. Detection of Aphanomyces euteiches races using a differential bean series. Plant Dis. Rep. 54:943-945.

4. Davis, D. W., Fritz, V. A., Pfleger, F. L., Percich, J. A., and Malvick, D. K. 1995. MN 144, MN 313, and MN 314: Garden pea lines resistant to root rot caused by Aphanomyces euteiches Drechs. HortScience 30:639-640.

5. Delwiche, P. A., Grau, C. R., Holub, E. B., and Perry, J. B. 1987. Characterization of Aphanomyces euteiches isolates recovered from alfalfa in Wisconsin. Plant Dis. 71:155-161.

6. Dick, M. W. 1973. Saprolegniales. Pages 113-144 in: The Fungi: An Advanced Treatise. Vol. IVB. G. C. Ainsworth, F. K. Sparrow, and A. S. Sussman, eds. Academic Press, Orlando, FL.

7. Freeman, S., Katan, T., and Shabi, E. 1996. Characterization of Colletotrichum gloesporoides from avocado and almond fruits with molecular and pathogenicity tests. Appl. Environ. Microbiol. 62:1014-1020.

8. Gosselin, L., Jobidon, R., and Bernier, L. 1995. Assessment of genetic variation within Chondrostereum purpureum from Quebec by random amplified polymorphic DNA analysis. Mycol. Res. 100:151-158.
9. Grau, C. R., Muehlchen, A. M., Tofte, J. E., and Smith, R. R. 1991. Variability in virulence of Aphanomyces euteiches. Plant Dis. 75:11531156.

10. Gritton, E. T. 1990. Registration of five root rot resistant germplasm lines of processing pea. Crop Sci. 30:1166-1167.

11. Hagedorn, D. J., ed. 1984. Compendium of Pea Diseases. The American Phytopathological Society, St. Paul, MN.

12. Hamelin, R. C. 1996. Genetic diversity between and within cankers of the white pine blister rust. Phytopathology 86:875-879.

13. Holub, E. B., Grau, C. R., and Parke, J. L. 1991. Evaluation of the forma specialis concept in Aphanomyces euteiches. Mycol. Res. 95:147-157.

14. Huff, D. R., Peakall, R., and Smouse, P. E. 1993. RAPD variation within and among natural populations of outcrossing buffalograss [Buchlö̈ dactyloides (Nutt.) Engelm.]. Theor. Appl. Genet. 86:927-934.

15. Kraft, J. M. 1992. Registration of 90-2079, 90-2131, and 90-2322 pea germplasms. Crop Sci. 32:1076.

16. Leung, H., Nelson, R. J., and Leach, J. E. 1993. Population structure of plant pathogenic fungi and bacteria. Pages 157-205 in: Advances in Plant Pathology. Vol. 10. J. H. Andrews and I. C. Tommerup, eds. Academic Press, London.

17. Lynch, M., and Milligan, B. G. 1994. Analysis of population genetic structure with RAPD markers. Mol. Ecol. 3:91-99.

18. Malvick, D. K., Grau, C. R., and Percich, J. A. 1998. Characterization of Aphanomyces euteiches strains based on pathogenicity tests and random amplified polymorphic DNA analysis. Mycol. Res. 102:465-475.

19. Malvick, D. K., and Percich, J. A. 1998. Variation in pathogenicity and genotype among single zoospore strains of Aphanomyces euteiches. Phytopathology 88:52-57.

20. Manning, M. A., and Menzies, S. A. 1984. Pathogenic variability in isolates of Aphanomyces euteiches from New Zealand soils. N.Z. J. Agric. Res. 27:569-574.

21. McDonald, B. A., and McDermott, J. M. 1993. Population genetics of plant pathogenic fungi. BioScience 43:311-319.

22. Mitchell, J. E., and Yang, C. Y. 1966. Factors affecting growth and development of Aphanomyces euteiches. Phytopathology 56:917-922.

23. Munkvold, G. P., and Carlton, W. M. 1995. Prevalence and distribution of Aphanomyces euteiches and Phytophthora medicaginis in Iowa farm fields. Plant Dis. 79:1251-1253.

24. Paffetti, D., Scotti, C., Gnocchi, S., Fancelli, S., and Bazzicalupo, M. 1996. Genetic diversity of an Italian Rhizobium meliloti population from different Medicago sativa varieties. Appl. Environ. Microbiol. 62:2279-2285.

25. Papavizas, G. C., and Ayers, W. A. 1974. Aphanomyces species and their root diseases in pea and sugarbeet. U.S. Dep. Agric. Agric. Res. Serv. Tech. Bull. No. 1485.

26. Peever, T. L., and Milgroom, M. G. 1994. Genetic structure of Pyrenophora teres with random amplified polymorphic DNA markers. Can. J. Bot. 72:915-923.

27. Pfender, W. F., Delwiche, P. A., Grau, C. R., and Hagedorn, D. J. 1984. A medium to enhance recovery of Aphanomyces from infected plant tissue. Plant Dis. 68:845-847.

28. Pfender, W. F., and Hagedorn, D. J. 1982. Aphanomyces euteiches f. sp. phaseoli, a causal agent of bean root and hypocotyl rot. Phytopathology 72:306-310.

29. Raeder, U., and Broda, P. 1985. Rapid preparation of DNA from filamentous fungi. Lett. Appl. Microbiol. 1:17-20.

30. Scott, W. W. 1961. A monograph of the genus Aphanomyces. Va. Agric. Exp. Stn. Tech. Bull. 151.

31. Sundheim, L. 1972. Physiologic specialization in Aphanomyces euteiches. Physiol. Plant Pathol. 2:301-306.

32. Welsh, J., and McClelland, M. 1990. Fingerprinting genomes using PCR with arbitrary primers. Nucleic Acids Res. 18:7213-7218.

33. Williams, J. G. K., Kubelik, A. R., Livak, K. J., Rafalski, J. A., and Tingey, S. V. 1990. DNA polymorphisms amplified by arbitrary primers are useful as genetic markers. Nucleic Acids Res. 18:6531-6535.

34. Yap, I., and Nelson, R. J. 1996. WinBoot: A program for performing bootstrap analysis of binary data to determine the confidence limits of UPGMA-based dendograms. IRRI Discussion Paper Series No. 14. International Rice Research Institute, Manila, Philippines. 